$\begin{gathered}\text { EPiC Series in Built Environment } \\ \text { Volume 2, 2021, Pages 377-386 }\end{gathered}$
ASC 2021. 57th Annual Associated Schools
of Construction International Conference

\title{
Construction Management Teaching Methods and Assignments: Perception versus Reality
}

\author{
Robert Coffey and Shima Clarke \\ Clemson University \\ Clemson, South Carolina
}

Higher education learning occurs through activity in and out of the classroom, whether it is physical or online. Instructors lecture, demonstrate, discuss, explain, and question students in the classroom and assign homework to reinforce learning outside of the classroom. Incorporating proven pedagogy into this process begins with exploring current approaches, the first step of benchmarking. This paper presents a small part of a broader scientific inquiry that sought to understand how construction management students learn best and examine current methodologies and how they compare to evidence-based practices. The initial survey results illustrate the coherence between students and instructors on course delivery and reveal discrepancies between the time instructors plan and students spend on homework. The data are essential for course planning and improvement, especially if homework continues to be part of the learning process.

Key Words: Construction Management, Benchmarking, Teaching, Modality, Homework, Assignments, Tools

\section{Introduction}

This research was part of a larger project seeking to achieve a high level of excellence in construction management education. The study uses benchmarking to determine the path forward based on current performance and how it compares to industry best practices (Elmuti \& Kathawala, 1997). The focus for the present research is on higher education generally and construction management education specifically. Elmuti \& Kathawala (1997) references Matters and Evans (1996) in discussing benchmarking's five-stage process. The first two stages involve planning and team creation, the third stage, data collection and the focus of the present research, and the fourth and fifth stages, analysis and action (Elmuti \& Kathawala, 1997). According to Elmuti \& Kathawala (1997), the first step in data collection is to identify the internal processes.

\section{Background}

Fernández-Balboa \& Stiehl (1995) point out that few professors are trained as educators, but many are excellent, possibly due to their "mastery of a field of knowledge." Nilson (2010), on the other hand, describes an environment not long ago where no one cared what the instructors did in the classroom. Attitudes on what instructors do in the classroom appear to have changed over the last couple of 
decades, according to Nilson (2010), leading to instructional methods that have an impact on student learning. Perhaps one catalyst for instructional design awareness was Congressional approval in 1998 of the Comprehensive Reform Program, which led to the evidence-based approach (Slavin, 2002).

Psychologists' research on learning began in the late 1800s (Ormrod, 2012). Over the last century, researchers have proposed many principles and theories, often complementary, to explain the concept of learning and explain how humans learn (Ormrod, 2012). Nilson (2010) uses these principles and theories to provide a practical, research-based teaching approach in higher education. Students also have strong opinions on effective teaching practices, as evidenced by Bernold's (2005) summary of a survey of 100 civil engineering students. No students in the survey ranked textbook study, active class participation, and searching for information as effective. Still, a high percentage ranked tests similar to homework, work example problems in class, and well-organized lectures as effective (Bernold, 2005).

The students' opinions on effective teaching practices from Bernold (2005) were the impetus for our research questions to begin the benchmarking process. The questions, 1. Are instructors' and students' perceptions of teaching modality and tools congruent? 2. Are instructors' and students' perceptions of homework congruent? If instructors' and students' perceptions differ, it may explain why students find certain teaching practices ineffective and provide insightful information to instructors on teaching practice efficacy. To answer these questions, we surveyed instructors and students and analyzed the results to determine if perception discrepancies exist. This information is important to inform instructors on the perception-reality gap, if it exists, and suggest research-based instructional design changes to reduce the gap and improve learning.

We begin with a discussion of our methodology, followed by the survey results and discussion, and conclude with recommendations.

\section{Methodology}

Survey questions on course content were derived from Bernold's (2005) summary on students' views of whether specific teaching practices were effective or ineffective. Bernold (2005) measured the students' responses to textbook reading, class participation, independent research, oral quizzes, tests reflecting homework and example problems, working example problems in class, and well-organized lectures. Conversations with instructors at the University about classroom activity, tools used, and homework reflected Bernold's (2005) study with slight differences discussed below in the section on survey creation. The following sections detail the researchers' methodological approach.

\section{Survey Instrument Selection}

The survey instrument selected for the research was QualtricsXM, without consideration of other tools for two reasons: The University's Qualtrics license permits its use for researchers at the University without additional cost; and two, Qualtrics has the functionality required to build, test, and distribute the survey according to the researchers' design intent which includes email distribution and follow-up, logic workflows that modify and skip questions based on prior answers, the ability to download and structure the response data, automated portable device optimization, and automated survey analysis to determine confusing questions, accessibility issues, and survey success. 


\section{Survey Creation}

Separate surveys were created for instructors and students because of the respondents' point of view, and the research included a learning styles survey for the students that is not addressed in this paper. In adherence to the University's Institutional Review Board's guidelines, the surveys' first page provided a summary of expectations, followed by a page for participant consent. Following consent, the survey began by asking the respondent to select which courses they completed (or taught) or are currently taking (or teaching), followed by which semester they took the course. Knowing when students took and instructors taught a course allows the researchers to see if modality and tools change over time.

Sliders were used for responses to survey questions on modality and tools used to allow students and instructors to effortlessly project their perception of the time spent over a semester. Moving the slider to the left for less time and to the right for more time provided a visual cue to the respondent with unlimited options. The slider data was normalized into percentages totaling 100 percent for each student/course response. The survey question regarding classroom activity included the options Lecture, Question and Answer, Discussion, Working Through Problems, and Demonstrations. The survey question regarding tools had the options PowerPoint, Whiteboard, Lightboard, and Other. The survey presented the respondent with an additional question to list the other tools if the Other slider value was greater than zero.

Multiple-choice responses were used for homework in the categories of textbook reading, nontextbook reading, required video, individual projects, and group projects. The responses were hour ranges spent on each of the activities, with four options provided, $0,>0 \&<1,>1 \&<3$, and $>3$ (Berry, Cook, Hill, \& Stevens, 2010).

The researchers performed a series of survey quality control checks before survey distribution. The first quality control step was a cycle of error corrections and previews using the Qualtrics preview function. Following the preview process, the researcher provided an instructor with the survey through the Qualtics distribution system for review. The instructor feedback confirmed that the survey functioned as designed, and additional changes were unnecessary.

\section{Sampling Frame and Sample}

A complete list of active undergraduate students in the spring of 2019 with their email addresses and overall grade point averages (GPA) was obtained from the Department of Construction Science and Management (CSM) and saved in an encrypted excel file on a BitLocker encrypted USB flash drive. The sampling frame was all 208 undergraduate students in the list, and the study sample included the entire sample frame. Two students were omitted later because they did not have a GPA.

\section{Distribution}

The researchers created two contact lists in Qualtrics, one for the instructors and another for the students. They imported the instructors' and students' names and email addresses into these contact lists and distributed the surveys by email using the Qualtrics distribution functionality. The researchers used the Qualtrics administrative home page to monitor the number of responses and response trends to determine the timing for subsequent reminder emails. Instructors were responsive to the request, and no reminders were necessary. However, students were less responsive, so two 
reminder emails were distributed to non-respondents one week after the initial email and two weeks after the first reminder.

\section{Data Collection and Organization}

58 of the 208 (28\%) students completed the electronic survey. The text and numeric forms of the survey response data were downloaded from Qualtrics as Excel files and then combined in one Excel file on separate worksheets. The researcher added the students' class standing and GPA information from the sampling frame to the survey data before removing personally identifiable data. Qualtrics assigned a unique identifier for each completed survey, and Excel's random number function was used to create unique identifiers for students that did not complete the survey. The survey results produce a single record for each student, but analysis requires a single record for each student-course combination. Therefore, we parsed each record into several records, one for each course from each student's response. The researcher created another Excel spreadsheet with student GPAs by class standing but without personally identifiable information using the entire sample frame. The Excel spreadsheets were imported into the Statistical Analysis Software (SAS for Windows version 9.4) for analysis.

\section{Data Analysis}

The researchers chose SAS 9.4 for data analysis because it is flexible in its ability to model analysis through a programmable interface, and it is available through a University license. The SAS 2-sided ttest procedure (proc ttest) was used to perform a GPA comparison between the sample and the sampling frame to determine if the sample represents the sampling frame at a significance level of $p$ value $<0.05$. The SAS GLM procedure (proc glm) was used to make a similar comparison of the students stratified by class standing at a significance level of $\mathrm{p}$-value $<0.05$.

Additional two-sided t-test procedures were run to compare student and instructor responses to modality and tools used to determine if there was a significant difference at $p$-value $<0.05$. An analysis of homework required two procedures for analysis. First, the frequency procedure (proc freq) was run to produce tables of stratified responses by semester to determine changes over time. Second, the StatGraph render procedure (proc sgrender) produced summary pie charts for visual response comparisons between students and instructors. The researchers used Microsoft Excel for the final homework analysis and chart creation.

\section{Results and Discussion}

\section{Sample and Sampling Frame Comparisons}

The student survey response rate was $28 \%$ (58 of 206), and all 18 CSM courses were addressed in the responses. The instructor survey response rate was $62 \%$ (8 of 13) and 13 of the 18 CSM courses were addressed in the responses. There is evidence at a significance level of $\alpha=0.05$ (t-value $=-2.08 ; \mathrm{p}-$ value $=0.0387$ ) to conclude that the student sample's mean GPA is higher than that of the sampling frame. A stratified comparison lacks power compared to the sample to sampling frame comparison. Still, it demonstrates that our population and sample mean GPAs are statistically similar by class standing with p-values ranging from 0.094 to 0.667 . A comparison of GPA by class standing for both the sample and sampling frame do not provide enough evidence at a significance level of $\alpha=0.05$ ( $F$ $=1.98 \& 1.37 ; \mathrm{p}$-values $=0.1179 \& 0.2687$ respectively) to determine that they are different. In other words, all class standings have statistically similar GPAs. 


\section{Teaching Modality and Tools}

The predominant teaching modality/tool combination, according to both students and instructors in CSM, is a lecture with PowerPoint, supporting Worthington \& Levasseur (2015) observation that PowerPoint aided lectures are "omnipresent" as a teaching technique for higher education. Students and instructors agreed on the proportion of time spent on the other modalities. The modalities listed from more time to less time are working problems, questions and answers, discussion, and demonstrations. The students and instructors rated the use of these practices independently, and there is not enough evidence at a significance level of $\alpha=0.05$ to indicate that the perceived use of these modalities differs between students and instructors, except for questions and answers. Students determined questions and answers were used as a teaching practice $15 \%$ of the time, and instructors estimated it at $23 \%$.

Similarly, there is not enough evidence at a significance level of $\alpha=0.05$ to indicate that the students and instructors perceived frequency of in-classroom tool use differs. PowerPoint, at $62 \%$, was by far the tool used most often. It is followed by whiteboard at $24 \%$, Other at $8 \%$, and lightboard at $6 \%$. Other tools mentioned by the students and instructors are software, drawings, demonstrations, guest speakers, and handouts.

\section{Homework}

The analysis of work required outside of class produced some exciting results. Unlike course modality and teaching practices, work outside of class is student dependent and varies significantly between students and courses. There was a significant disparity between the time instructors felt was required for homework, and the time students reported spending on homework. The survey asks about time for reading textbooks, reading other material, watching video lectures, working on individual projects, and working on group projects. In addition to comparing the responses between students and instructors, a frequency table was created to evaluate the data over time to determine changes over the last several years. Each of the categories is addressed below.

\section{Reading Textbook}

Instructors estimated that there is no homework time required for reading a textbook for $23 \%$ of the courses, less than an hour per week for $39 \%$ of the courses, between one to three hours per week for $38 \%$ of the courses, and never more than three hours a week (see Figure 1B). The instructors' estimate of time for reading a textbook is in sharp contrast to what the students estimate. The average student response shows that $45.8 \%$ of the students do not read textbooks, $23.7 \%$ read textbooks less than an hour per week, $26 \%$ read textbooks between one and three hours per week, and $4.5 \%$ read textbooks for more than three hours per week (see Figure 1Figure 2A). There is no indication that the amount of time spent reading textbooks outside of class has changed over the last several years. 

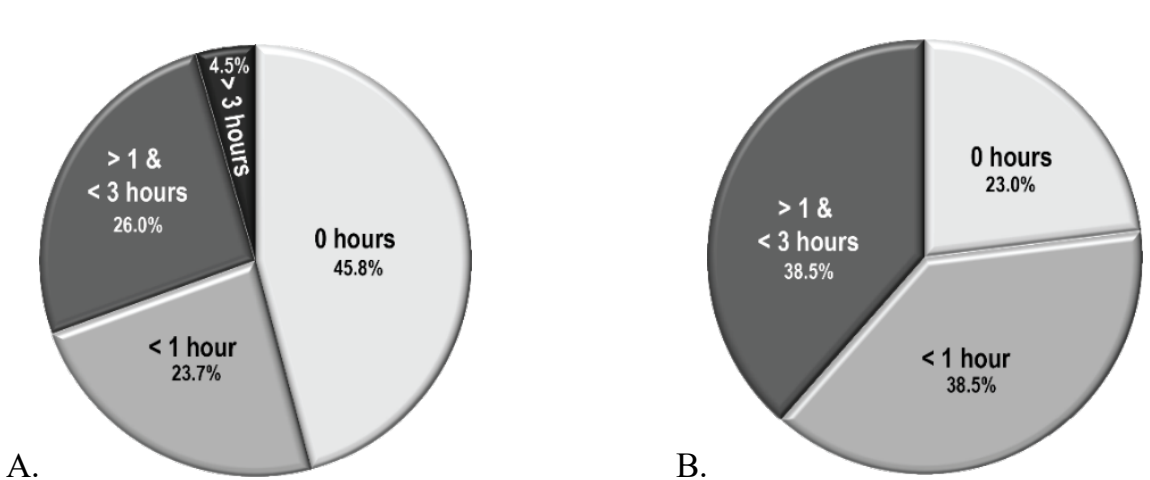

Figure 1. Hours per week reading a textbook as perceived by students (A) and instructors (B).

\section{Reading Non-textbook}

The instructors' estimate for non-textbook reading outside of class and student practices has the opposite results as those for reading textbooks. Instructors estimated that there is no additional reading for $53.8 \%$ of the courses, less than an hour per week for $30.8 \%$ of the courses, and between one to three hours per week for $15.4 \%$ of the courses (see Figure $2 \mathrm{~B}$ ). A large percentage of students $(49.2 \%)$ reported not reading non-textbook material, and another quarter reported reading less than an hour a week (see Figure 2A). Students reported spending more time reading at higher levels than estimated by instructors, with $20.9 \%$ of the students reporting reading between one and three hours and $4.2 \%$ reporting reading more than three hours. There is no indication that the amount of time spent on non-textbook reading outside of class has changed over the last several years.

A.

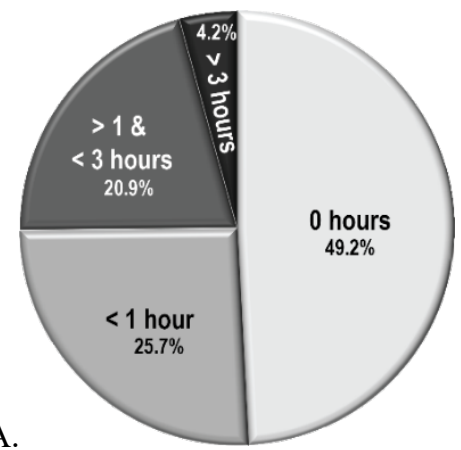

B.

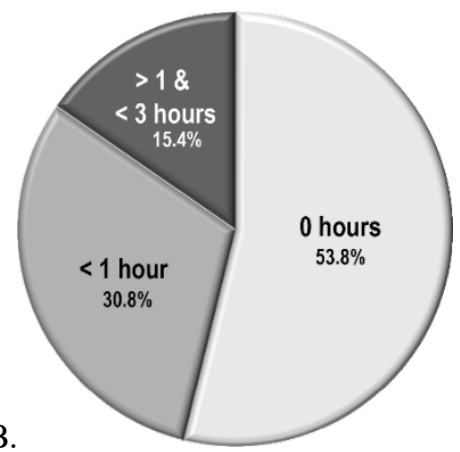

Figure 2. Hours per week reading material other than a textbook as perceived by students (A) and instructors (B).

\section{Required Video}

Instructors estimated that there is no homework time necessary for required videos for $53.8 \%$ of their courses, less than an hour per week for $30.8 \%$ of their courses, between one to three hours per week for $7.7 \%$ of their courses, and more than three hours per week for $7.7 \%$ of their courses (see Figure 3B). Videos appear to be less popular among students with $71.9 \%$ indicating that they do not watch videos (see Figure 3A). Still, the combination of students not watching videos to those watching less than an hour, 13.7\%, approximately matches the instructors' expectations. Students report equally on watching videos between one to three hours, and another and more than three hours per week at $7.2 \%$ 
each, which is approximately equivalent to the instructors' estimate. The frequency in the amount of time spent per week on video watching appears to be consistent over the years except for one course. The frequency analysis for a structures course shows a significant increase in time spent watching required videos that correspond to a modality shift from traditional lectures to a flipped classroom.

A.

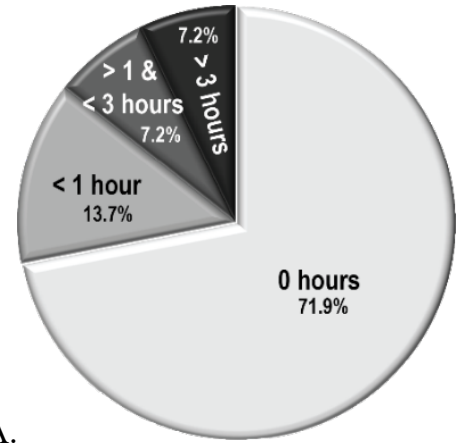

Figure 3. Hours per week watching videos as perceived by students (A) and instructors (B).

\section{Individual Projects}

Instructors estimated that there is no homework time required for individual projects for $15.4 \%$ of their courses, less than an hour a week for $38.5 \%$ of their courses, and between one and three hours a week for $46.1 \%$ of their courses (see Figure 4B). The number of students reporting that they spend no time on individual projects $(56 \%)$ outside of class is almost equal to the first two categories, no time and less than an hour, estimated by instructors (see Figure 4A). This means that students reporting any time on individual projects is approximately equal to instructors' estimates reporting more than an hour. Students who spend time on individual projects are divided between less than an hour, between one and three hours, and more than three hours. It appears that students that work on individual projects are spending more time on them than their instructors estimated. The frequency in the amount of time spent per week on individual projects appears to be consistent over the years except for one course. The frequency analysis for Emerging Technologies shows a slight increase in the time spent working on individual projects outside of class.

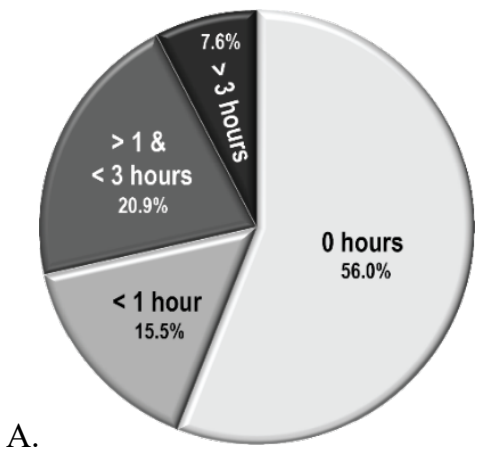

Figure 4. Hours per week working on individual projects as perceived by students (A) and instructors (B). 


\section{Group Projects}

Instructors' estimates and students' responses to time spent on homework for group projects are the most aligned. Instructors estimated that there is no homework time required for group projects for $46.2 \%$ of their courses, less than an hour a week for $15.4 \%$ of their courses, between one to three hours a week for $30.8 \%$ of their courses, and over three hours for $7.6 \%$ of their courses (see Figure 5B). Students reporting no hours outside of class on group projects $(51.6 \%)$ is slightly higher than instructors' estimate (see Figure 5A). Students that reported spending less than an hour or between an hour and three hours on group projects were lower than instructors' estimates at $13.9 \%$ and $19.2 \%$, respectively. Students who reported spending more than three hours per week on group projects were almost double the amount estimated by instructors at $15.3 \%$. There is no indication that the time spent on group projects outside of class has changed over the last several years.

A.

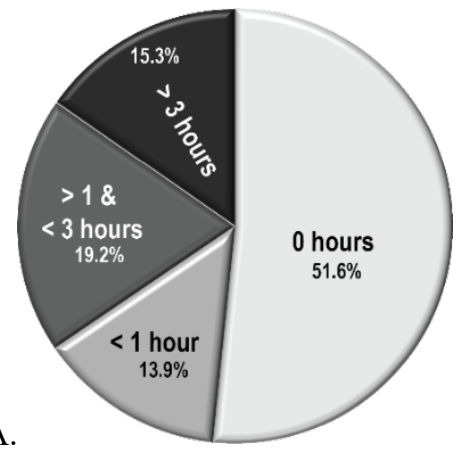

Figure 5. Hours per week working on group projects as perceived by

students (A) and instructors (B).

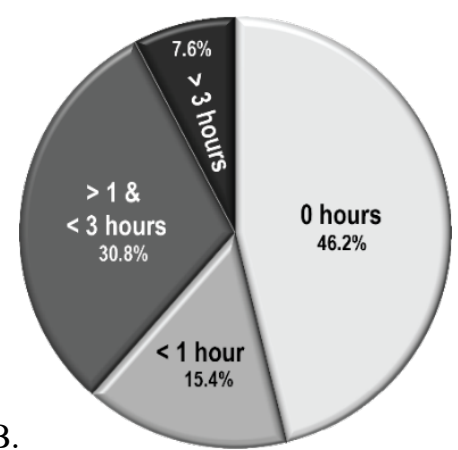

\section{Conclusion}

This research shows that students and instructors view course modality and tools the same, except for the level of question and answer time. The congruence of modality and tool perceptions between students and instructors is encouraging because it indicates that confusion regarding the course makeup is not likely to exist. The one disparity of question and answer sessions may be due to student and instructor roles and how they impact the perception of activity time. Students may perceive less time spent on the activity because the amount of time an individual student spends actively engaged in a question and answer session is a fraction of the time the instructor is involved. Jones (2007) provides some insight into why students might not participate in group discussion or question and answer sessions that include dominant students, students who lack a strong opinion, students who do not want to disagree, and students who lack confidence in expressing their thoughts.

Students report doing much less homework than their instructors predicted. Thirty percent (30\%) of students report that they do no homework for $44 \%$ of their construction courses and less than one hour per week for $67 \%$ of their construction courses. On the other hand, instructors predict that students will spend almost five hours per week per course on average on homework. In contrast to students doing less homework than expected, more time on homework occurs when students work on projects. Thirty percent $(30 \%)$ of students report spending more than three hours per week on both individual and group projects for seventeen percent (17\%) of their construction courses. Instructors predicted that individual and group projects would take less than three hours per week for all courses except one, Capstone. 
Reading and video watching have the smallest time commitment by students in this study, and projects have the most. These data support Berry et al. (2010) that there is a lack of reading among college students. Planchard et al. (2015) tell us that students are motivated to complete homework for the benefit of learning but were more likely to do so when the work is graded. Research demonstrates that graded homework positively correlates with academic success (Young, Dollman, \& Angel, 2016; Planchard, Daniel, Maroo, Mishra, \& McLean, 2015; Emerson \& Mencken, 2011). Students completing graded homework at a higher frequency than non-graded work is supported by the present research based on the time students reported spending on graded (projects) and non-graded (reading and video) assignments.

Instructors who feel students should spend more time on reading and video assignments should consider grading the activities; a task made easier with Learning Management Systems (LMS) and integrated software. An application available for reading called Perusall encourages interactive discussion on reading assignments. It automates grading based on the quality of each student's comments and measures how much each student reads. Camtasia, Ensemble, and other video software creation and distribution tools provide quiz capability during the video to help keep students engaged. The grading for these tools and others can be integrated with the LMS to minimize the instructor's work.

\section{References}

Bernold, L. E. (2005). Paradigm Shift in Construction Education is Vital for the Future of our Profession. Journal of Construction Engineering and Management, 131(5), 533-539. doi:10.1061/(ASCE)0733-9364(2005)131:5(533)

Berry, T., Cook, L., Hill, N., \& Stevens, K. (2010). An exploratory analysis of textbook usage and study habits: misperceptions and barriers to success. College Teaching, 59(1), 31-39. doi: $10.1080 / 87567555.2010 .509376$

Elmuti, D., \& Kathawala, Y. (1997). An overview of benchmarking process: A tool for continuous improvement and competitive advantage. Benchmarking for Quality Management \& Technology, 4(4), 229-243.

Emerson, T. L., \& Mencken, K. D. (2011). Homework: To require or not? Online graded homework and student achievement. Perspectives on Economic Education Research, 7(1), 20-42.

Fernández-Balboa, J.-M., \& Stiehl, J. (1995, May). The Generic Nature of Pedagogical Content Knowledge Among College Professors. Teaching and Teacher Education, 11(3), 293-306.

Jones, L. (2007). The student-centered classroom. New York, NY: Cambridge University Press.

Matters, M., \& Evans, A. (1996). The nuts and bolts of benchmarking. Benchmarking Link-Up Australia.

Nilson, L. B. (2010). Teaching at its best, a research-based resource for college instructors, third edition. San Francisco: Jossey-Bass.

Ormrod, J. E. (2012). Human Learning, 6th ed. Upper Saddle River, NJ: Pearson Education, Inc.

Planchard, M., Daniel, K. L., Maroo, J., Mishra, C., \& McLean, T. (2015). Homework, motivation, and academic achievement in a college genetics course. Bioscene: Journal of College Biology Teaching, 41(2), 11-18.

Slavin, R. (2002, October 1). Evidence-Based Education Policies: Transforming Educational Practice and Research. Educational Researcher, 31(7), 15-21. doi:10.3102/0013189X031007015

Worthington, D. L., \& Levasseur, D. G. (2015). To provide or not to provide course PowerPoint slides? The impact of instructor-provided slides upon student attendance and performance. Computer \& Education, 85, 14-22. 
Young, N., Dollman, A., \& Angel, N. F. (2016). Does homework really matter for college students in quantitatively-based courses? Journal of Learning in Higher Education, 12(1), 19-26. 